\title{
RP31
}

\section{Rock Physics Modeling for Waterflood Simulation: A Case History from the Burgan Field, Kuwait}

K. Edwards* (Kuwait Oil Company), M. Ebrahim (Kuwait Oil Company), F. Qassim (Kuwait Oil Company) \& S. Al-Asfour (Kuwait Oil Company)

\section{SUMMARY}

We show with some simple code, a wide range of possible scenarios can be simulated and visualized. Based on our simulations, we conclude that a water flood in the Burgan and/or Wara formations should be visible as an amplitude change on 4D seismic with a water flood thickness of at least 15 feet. 


\section{Introduction}

In order to monitor a water flood in the Wara and Burgan reservoirs of the Burgan field in Kuwait, 4D seismic was considered. To evaluate the feasibility of 4D seismic, Rock Physics modelling was performed using Gassmann's equation (Gassmann, 1951) for fluid substitution. We developed a method to calculate many scenarios and store the results in a set of $3 \mathrm{D}$ seismic volumes.

Rock Physics modelling is typically done to assess the integrity of measured logs and to create a full set of elastic logs that can be used to calculate synthetic seismograms. For a given model, parameters such as porosity, shale content and fluid content can be altered and the effect on seismic can be seen.

The Burgan and Wara reservoirs span almost 1000 feet of thickness which is approximately $150 \mathrm{~ms}$ in two way travel time. In order to simulate a water flood, we must consider that the oil/water contact could be anywhere in the reservoir interval. Simulation of a water flood often involves many variables such as the efficiency of the water flood, the location of the oil-water contact relative to the geology and the thickness of the flooded zone. Typically only a small subset of all possibilities is modelled. In this paper we demonstrate a method to model many possible scenarios by splicing modelled logs into a 3D volume. In addition, we also introduce an alternate measure of amplitude change which we refer to as the Normalized Amplitude Envelope Difference (NAED).

\section{Method}

We simulate three water saturation cases: below original OWC ( $\mathrm{Sw}$ equals $100 \%$ ), above new OWC ( $\mathrm{Sw}$ equals bound water only), and within water flood zone ( $\mathrm{Sw}$ equals some value that represents the saturation achieved by the water flood.) Given that any of these three cases could exist at any level of the reservoir, we first build logs for the three cases where the entire reservoir interval is altered. We then build a 3D volume of composite logs by splicing the appropriate sections from the three cases. For each OWC level, we then simulate a water flood thickness from 5-100 feet. This thickness varies with inline number (Figure 2a) and the depth of the contact will vary with crossline number (Figure 1). Multiple 3D volumes are generated to show different water saturations in the water flood zone.

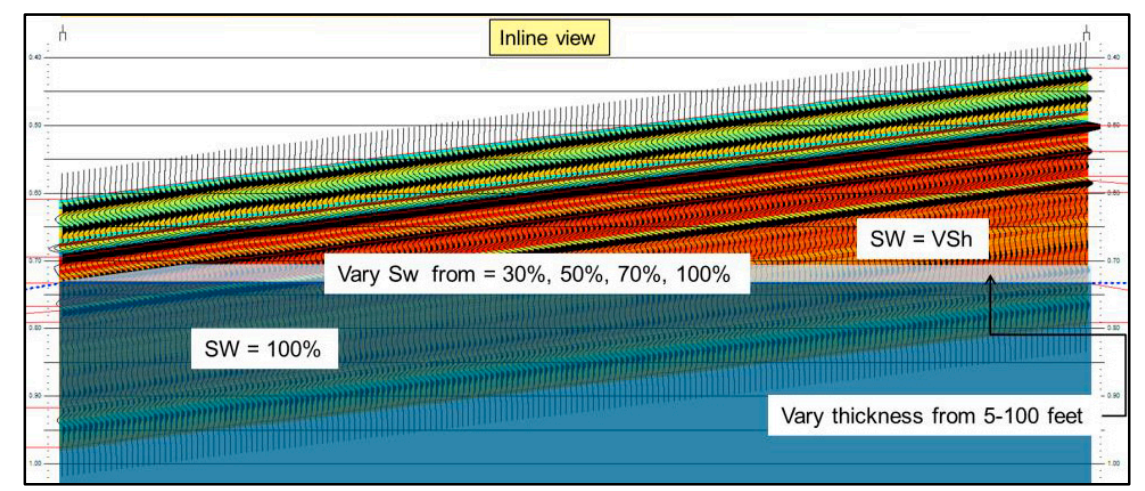

Figure 1 This figure illustrates the three variables we consider in our simulation. The first is the position of the oil/water contact shown changing with each trace in the inline view. The second variable is the thickness of the water flooded zone which would be visible in the crossline view. The third variable is the water saturation in the flooded zone. Multiple $3 D$ volumes will be used represent changing $S w$ in the flooded zone.

After these volumes are created, we can compute difference volumes. From the difference volume we calculate the Normalized Amplitude Envelope Difference (NAED) by dividing the value of the 
amplitude envelope of the difference by the average amplitude envelope value of the base case traces. We use amplitude envelope because it is independent of phase and it relates directly to the amplitude of the trace and hence reflectivity (Figure $2 b$ ).

\section{Discussion}

Our current approach only models the zero offset case and as such does not consider AVO effects. This approach could be modified to include modelling gathers and calculating and displaying AVO attributes. With seismic workstations ability to view inline, crossline, time and horizon slices as well as multiple volumes, we can quickly visualize the magnitude of changes across our reservoir as a function of many variables.

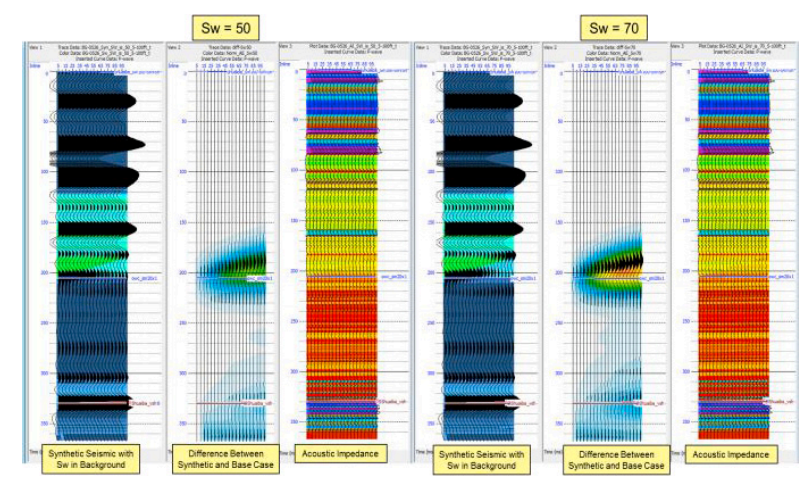

(a)

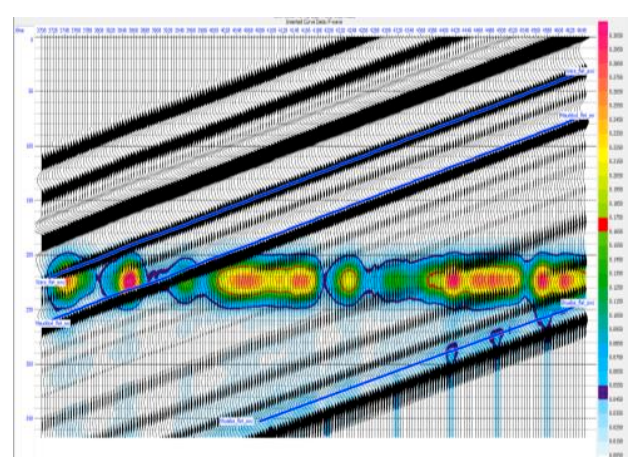

(b)

Figure 2 This figure shows (a) the results of simulation of two different water saturations as well as the monitor-base case difference for a particular oil/water contact level. (b) The NAED attribute for 25 feet of water flood at $S w=70 \%$ is displayed in the background of the $S w=70 \%$ scenario synthetic with $5 \%$ and $17 \%$ NAED values highlighted as purple and red contours.

\section{Conclusions}

We have shown with some simple code, a wide range of possible scenarios can be simulated and visualized. Based on our simulations, we conclude that a water flood in the Burgan and/or Wara formations should be visible as an amplitude change on 4D seismic with a water flood thickness of at least 15 feet.

\section{Acknowledgements}

We would like to thank the Minister of Oil, Kuwait, Exploration Manager KOC, Team Leader and colleagues in the Geophysical Solutions team KOC, and our colleagues in the Greater Burgan Studies team.

\section{References}

Gassmann, F. [1951] Über die elastizität poröser medien: Vierteljahrss-chrift der Naturforschenden Gesellschaft in Zurich, 96, 1-23. 